\title{
A CONCEPÇÃO DA DISCRIMINAÇÃO COMO FATOR DE VIOLAÇÃO AOS DIREITOS HUMANOS E SUAS CONTRIBUIÇÕES AO PLANO NACIONAL DE EDUCAÇÃO
}

\author{
Adriana Regina de Jesus Santos ${ }^{1}$ \\ Allan Tivanello Gusmão Tivanello ${ }^{2}$ \\ Lucas Henrique dos Santos ${ }^{3}$
}

\begin{abstract}
Resumo: o artigo tem como objetivo compreender como a discriminação é representada por meio dos relatórios nacionais sobre Direitos Humanos no Brasil (RDNH) realizado pelo Núcleo de Estudos da Violência da Universidade Estadual de São Paulo (NEV/USP), no que se refere as mulheres, negros e LGBTs. Para tanto, a metodologia utilizada nesta pesquisa tem como base o estudo teórico e documental. Ao término do estudo constatou-se por meio dos relatórios que o recorte que trata de grupos minoritários no Brasil tem ganhado visibilidade na produção dos relatórios e estes enfatizam a necessidade de políticas voltadas a preservação da dignidade da pessoa humana, do combate à discriminação, passos esses importantes para a emancipação de negros, mulheres e LGBTs.
\end{abstract}

Palavras-chave: DireitosHumanos. Discriminação. Mulheres. Orientação Sexual. Política.

\section{The conception of discrimination as a factor of violation of human rights and its contributions to the National Education Plan}

\begin{abstract}
: the article aims to understand how discrimination is represented through national reports on human Rights in Brazil (RDNH) conducted by the Center for Violence Studies of the State University of São Paulo (NEV/USP), with regard to the Women, blacks and LGBTs. For this purpose, the methodology used in this research is based on the theoretical and documentary study. At the end of the study, it was verified through the reports that the clipping that deals with minority groups in Brazil has gained visibility in the production of the reports and these emphasize the need for policies aimed at preserving the dignity of the human person, of combating discrimination, steps that are important for the emancipation of Blacks, women and LGBTs.
\end{abstract}

Key Words: Human rights, education, discrimination

\footnotetext{
'Universidade Estadual de Londrina. (adrianatecnologia@yahoo.com.br)

${ }^{2}$ Universidade Estadual de Londrina. (adrianar@uel.br)

${ }^{3}$ Universidade Estadual de Londrina. (lucas.henriquebio@outlook.com)
}

$$
\begin{array}{lll}
\text { v. } 21 \text { n. } 48 & \text { p. } 220-235 & \text { out./dez. } 2019
\end{array}
$$




\section{INTRODUÇÃO}

O reconhecimento do problema da discriminação no Brasil é um passo importante para a mudança da realidade social composta de injustiças históricas que acabam por gerar processos de exclusão de grupos minoritários como mulheres, negros e LGBTOs. Conforme afirma Floresta Fernandes o brasileiro tem preconceito do preconceito e por isso busca negar e não dialogar sobre os grupos que sofrem com a discriminação por parte de uma maioria social.

Apesar da negação do problema os fatos e a realidade social brasileira evidencia que o país se encontra distante de viver livre do preconceito e da discriminação. Ao observarmos os dados da violência contra mulheres, negros e LGBTOs vemos um aumento das taxas de feminicídio, um assassinato de jovens negros por parte de agentes do Estado e as maiores taxas de violência contra LGBTOs do mundo.

No contexto da sociedade contemporânea é possível constatar que o Brasil apresenta uma série de desafios para implementar e formular políticas voltadas aos direitos humanos. Podemos afirmar que existe uma necessidade de redefinir o significado e as práticas de direitos humanos no Brasil na tentativa de uma abordagem teórica e práticas diferenciadas na qual os grupos minoritários como mulheres, negros e LGBTOs sejam contemplados.

A escolha pela abordagem desses grupos se remete a um movimento feito por organismos internacionais que combatem as diferentes formas de discriminação. A ONU organizou convenções internacionais no combate a todas formas de discriminação contra mulheres e mulheres e declarou em 2011 que direitos LGBTOs são direitos humanos.

Além disso, núcleo de estudos em diferentes universidades tem avançado no entendimento dos direitos de mulheres, negros e LGBTOs. O Núcleo de Estudos da Violência da Universidade Estadual de São Paulo produziu cinco relatórios nacionais que abordam a temática de violações aos direitos humanos e conforme o avanço das publicações houve o avanço nos debates sobre os direitos desses grupos.

Isto posto para uma melhor compreensão deste fenômeno da discriminação e a valorização dos debates sobre direitos humanos e grupos minoritários analisamos os Relatórios Nacionais sobre Direitos Humanos no Brasil oriundos do Núcleo de Estudos da Violência da Universidade Estadual de São Paulo (NEV/USP) que apresentam uma série de violações aos Direitos Humanos ocorridas no país no século XXI. De acordo com esses relatórios: 
Não houve progresso na formulação e implementação de políticas de Direitos Humanos e, em certas áreas, em particular na área dos direitos civis, houve um recesso, poder-se-ia dizer até abandono, de um projeto de universalização e equalização do acesso aos Direitos Humanos (BRASIL, 2007, p. 16).

Destarte, o objetivo deste estudo é compreender como a discriminação é representada por meio dos relatórios nacionais sobre Direitos Humanos no Brasil (RDNH) realizado pelo Núcleo de Estudos da Violência da Universidade Estadual de São Paulo (NEV/USP), no que se refere as mulheres, negros e LGBTs. Para tanto a metodologia teve como base a pesquisa teórica e documental. Foram selecionados cinco relatórios produzidos pelo Núcleo de Estudos da Violência da Universidade Estadual de São Paulo, são eles: I Relatório nacional sobre Direitos Humanos no Brasil produzido em 2002, II Relatório nacional sobre Direitos Humanos no Brasil elaborado em 2005, III Relatório nacional sobre Direitos Humanos no Brasil elaborado em 2007, IV Relatório nacional sobre Direitos Humanos no Brasil elaborado em 2010, e V Relatório nacional sobre Direitos Humanos no Brasil elaborado em 2012, tendo como foco identificar possíveis oposições e correlações das violações aos direitos humanos em relação a discriminação desses grupos minoritários. Entretanto somente o segundo, terceiro, quarto e quinto apresentaram aspectos relacionados a violações contra grupos minoritários, bem como, apresentaram uma diversa fonte teórica e documental de dados a serem analisados.

Para uma melhor compreensão do tema estudado, contextualizaremos a seguir a discriminação como violação aos direitos humanos no país e analisaremos a discriminação como fator de violação de direitos humanos a partir de apontamentos feitos pelos relatórios nacionais.

\section{CONTEXTO HISTÓRICO DA DISCRIMINAÇÃO NO BRASIL}

Para análise da discriminação no Brasil é importante ressaltar o contexto mundial na abordagem do tema sobre discriminação e sua relação com os direitos humanos. Somente com a Declaração Universal dos Direitos Humanos em 1948 a discriminação passou a ser pauta do direito internacional e ganhou uma importância significativa na ideia da efetivação dos direitos e da cidadania de grupos minoritários a partir de uma perspectiva multicultural. 
Com a "Convenção Internacional sobre a Eliminação de Todas as formas de Discriminação racial" em 1965 e a "Convenção sobre a eliminação de todas as formas de discriminação contra as mulheres" em 1979 houve mudanças na concepção de direitos humanos e como deveriam ser direcionadas as políticas para efetivação desses direitos que necessitavam de uma análise particular para cada grupo.

Sendo assim, por meio das convenções a ideia de universalidade dos direitos humanos passou a ser repensada uma vez que os grupos minoritários possuem demandas específicas que precisam ser contempladas nas políticas públicas para que as necessidades de cada grupo sejam superadas.

A discriminação é um fator que age na contramão da dignidade da pessoa humana e impede o exercício pleno dos direitos sociais, políticos, civis e principalmente dos direitos humanos. No caso do Brasil apesar de avanços no debate da discriminação ainda existem muitos desafios para serem superados, mas tivemos avanços na defesa desses direitos:

Nos últimos anos, as organizações da sociedade civil que lutam pelos direitos de grupos minoritários têm obtido diversos avanços no que diz respeito a mudanças na legislação que coíbe manifestações de comportamentos e atitudes discriminatórios (Pereira, Torres, \& Almeida, 1988, p. 95).

Um exemplo que pode ser citado no país é a criminalização do racismo que data 1989 com a homologação da Lei n 7.716 que coloca a discriminação racial como um crime inafiançável, além disso, a Lei $\mathrm{n}^{\circ} 11.340$ que cria mecanismos para coibir a violência familiar e doméstica contra a mulher são exemplos de avanços contra a discriminação e suas consequências para os chamados grupos minoritários.

Apesar da criação de novas leis a efetividade na prevenção contra a discriminação é um fator que precisa ser analisado em pesquisas. Além disso, no país a temática racial, de gênero e sexualidade necessita ter uma abrangência mais significativa na sociedade civil e nos representantes do Estado.

Os desafios colocados pela temática racial, por exemplo, coloca em chegue uma discussão sobre a ideia de que o Brasil não seria um país racista e que haveria uma harmonia entre raças no país, tese defendida por Gilberto Freyre que configurou a chamada Democracia Racial, desmistificada por Florestan Fernandes nos seus estudos sobre raça e racismo principalmente nas 
obras "A inserção do negro na sociedade de classes" e "O negro no mundo dos brancos".

Sendo assim, o problema da discriminação de Gênero persiste na reprodução de desigualdades históricas como a dupla jornada de trabalho, a desigualdade salarial, a violência doméstica, a representatividade nos espaços de poder entre homens e mulheres e o feminicídio.

Quanto à temática dos LGBTOs existe uma dificuldade que impede de forma significativa a análise dos dados sobre a discriminação que tem por motivação a orientação sexual: a não criminalização desse tipo de discriminação. Esse fato impede o levantamento de dados e proteções específicas por parte do Estado por meio de políticas públicas direcionadas para esse grupo.

A igualdade perante a lei é um princípio que rege o Comitê de Direitos Humanos da ONU e a não discriminação é um fator que garante esse princípio:

De acordo com o Comitê de Direitos Humanos da ONU, em seu parágrafo 1: A não discriminação, juntamente com a igualdade perante a lei e a igual proteção da lei, sem qualquer tipo de discriminação, constitui um princípio básico e geral relativo à proteção dos direitos humanos (ADAMATTI, 2014, p. 93).

Nesse sentido a discriminação se constitui como um fator de preocupação dos órgãos internacionais que impedem a efetividade da lei de forma igualitária. Além do comitê as comissões que discutiram a discriminação, foram um fator importante para que os direitos humanos fossem direcionados de forma específica para grupos minoritários. De acordo com a comissão sobre a discriminação racial a definição se expressa da seguinte forma:

Nesta Convenção, a expressão 'discriminação racial' significará qualquer distinção, exclusão restrição ou preferência baseadas em raça, cor, descendência ou origem nacional ou étnica que tem por objetivo ou efeito anular ou restringir o reconhecimento, gozo ou exercício num mesmo plano (em igualdade de condição), de direitos humanos e liberdades fundamentais no domínio político econômico, social, cultural ou em qualquer outro domínio de vida pública" (ADAMATTI, 2014, p. 94).

A tentativa de superação da discriminação racial no Brasil necessita de grandes avanços nos debates sobre raça e racismo no país principalmente no convencimento da sociedade civil, pois a prática do racismo no Brasil se 
constitui de forma velada, mas que impede a população negra ao acesso aos direitos fundamentais.

A convecção contra as formas de discriminação contra a mulher define que a discriminação contra a mulher também é um fator que impede a igualdade entre homens e mulheres "em face do significado contemporâneo dos direitos humanos, a igualdade requer mesmo respeito e consideração advinda da dignidade, ao contrário da adoção de tratamentos iguais e homogêneos” (BRAGATO \& BIANKA, 2014):

Para os fins da presente Convenção, a expressão 'discriminação contra a mulher' significará toda a distinção, exclusão ou restrição baseada no sexo e que tenha por objeto ou resultado prejudicar ou anular o reconhecimento, gozo ou exercício pela mulher, independentemente de seu estado civil, com base na igualdade do homem e da mulher, dos direitos humanos e liberdades fundamentais nos campos político, econômico, social, cultural e civil ou em qualquer outro campo (ADAMATTI, 2014, p. 94).

Dessa forma a discriminação no país contra as mulheres bem como da população negra e dos LGBTOs tem como propósito ou efeito anular ou prejudicar o reconhecimento, o gozo e o exercício em pé de igualdade dos direitos humanos e das liberdades fundamentais (BRAGATO \& BIANCA, 2014). Não se pode mais pensar em igualdade como um princípio que exige apenas em considerações formais. É preciso reconhecer a dinâmica das relações de poder e compreender a situação de grupos e indivíduos historicamente em desvantagem.

Nesse sentido a tendência de direcionar a discussão dos direitos humanos para grupos minoritários tem sido um movimento observado na produção dos relatórios nacionais como veremos a seguir. É possível observar a partir das divisões dos capítulos dos relatórios que na produção do V Relatório Nacional Sobre Direitos Humanos foi dedicado um capítulo específico para cada tipo de discriminação (mulheres, negros e LGBTOs) esse fenômeno só é possível observar no último relatório o que indica um avanço das discussões sobre direitos humanos desses grupos no interior da elaboração desses relatórios. 


\section{A REPRESENTAÇÃO DA DISCRIMINAÇÃO COMO VIOLAÇÃO DE DIREITOS ENTRE MULHERES, NEGROS E LGBTOS NA ÓTICA DOS RELATÓRIOS NACIONAIS}

A partir da análise realizada por meio dos quatro relatórios nacionais sobre direitos humanos observa-se que a construção de consensos para a formulação de políticas globais não foi elaborada de forma devida no país uma vez que a implementação de políticas não foi efetiva. Esse dado pode-se constatar na descrição do segundo relatório quando este aponta que as mulheres "têm menos garantias de acesso à justiça e mais dificuldade de se organizar e se mobilizar para lutar em defesa de seus direitos" (BRASIL, 2002, p. 18).

De acordo com o segundo relatório as desigualdades enfrentadas pelas mulheres tem raízes históricas que impedem a efetivação dos seus direitos, nas palavras dos elaboradores:

A violência de gênero é uma prática que se manifesta na violência física, sexual e psicológica promovida contra a mulher, intrínseca às relações de poder historicamente desiguais estabelecidas entre homens e mulheres, e sustentada por atitudes e valores enraizados na sociedade. A violência contra a mulher, em especial a que ocorre no âmbito doméstico e das relações intrafamiliares, acarreta sérias e graves consequências para o pleno desenvolvimento da mulher e sua inserção na sociedade, na política e no mercado de trabalho (BRASIL, 2002, p. 28).

Nesse sentido o combate à discriminação de gênero vem sendo inserido na agenda pública como uma forma de eliminar a violência contra as mulheres. Além disso, o relatório apresenta dados que evidenciam a desigualdade salarial entre homens e mulheres.

Outro aspecto abordado no segundo relatório refere-se as discriminações raciais, pois essas estão frequentemente relacionadas a injúria racial, agressão física, demissão injusta ou algum outro crime. De acordo com o relatório existe uma distorção no registro das ocorrências pela polícia e diversas ocorrências de racismo deixam de ser registradas, porque "as vítimas têm medo de serem agredidas outras vezes ou então porque não acreditam que a denúncia seja acatada e o agressor seja punido" (BRASIL, 2005, p. 280).

No que tange ao terceiro relatório o critério para analisar as desigualdades raciais se baseiam na violência, educação e mundo do trabalho. De acordo com Brasil: 
Os afro-descendentes (negros e pardos) têm risco maior do que os brancos de serem vítimas de violência. De 2000 a 2002, para cada branco, 2,77 afro-descendentes foram mortos vítimas de agressão, sendo registrado um aumento desta taxa de 2,60 em 2000 para 2,80 em 2002 [...] Em 2003, a taxa de analfabetismo era de $6,61 \%$ para a população branca e $13,26 \%$ para a população negra. A escolaridade média era de 7,97 anos de estudo para a população branca e 6,59 anos para população negra [...] A renda domiciliar média era de $\mathrm{R} \$ 403,98$ para população branca e de $\mathrm{R} \$ 216,31$ para população negra. O salário-hora médio era de $R \$ 4,39$ para população branca contra $R \$ 2,50$ para população negra (BRASIL, 2010, p. 33).

Por meio da análise do terceiro relatório constatamos que, apesar das mulheres estarem denunciando com mais frequência à violência de que são vítimas ainda não existem políticas efetivas que previnam a violência contra a mulher e que combatam a discriminação, conforme o referido relatório:

As mulheres denunciam cada vez mais as violências de que são vítimas, mas a grande maioria dos estados não tem programas e serviços capazes de atender, orientar e proteger as vítimas de violência doméstica e sexual, e muito menos políticas de prevenção da violência contra a mulher. (BRASIL, 2007, p. 13).

Portanto, as políticas voltadas para as mulheres ainda precisam ser mais efetivas na prevenção e no combate às violações aos seus direitos. Segundo Wollstonecraft (2016) existe a necessidade da independência da mulher que seria para a autora a grande benção da vida. A discriminação é um dos fatores que impede as mulheres de usufruem de seus direitos e terem liberdade.

No quarto relatório a discussão sobre a discriminação contra mulher é evidenciada pelas desigualdades entre homens e mulheres no que tange as taxas de analfabetismo, renda familiar, violência sexual e doméstica, especialização do trabalho e taxas de natalidade. Observou-se nesse relatório também, que a construção dos direitos das mulheres está relacionado com a ação de órgãos internacionais e a criação de leis no país a partir do caso Maria da Penha Maia Fernandes, de acordo com os elaboradores do relatório:

Em 1998, o CEJIL-Brasil (Centro para a Justiça e o Direito Internacional) e o CLADEM-Brasil (Comitê Latino-americano do Caribe para a Defesa dos Direitos da Mulher), juntamente com a vítima Maria da Penha Maia Fernandes, encaminharam à Comissão Interamericana de Direitos Humanos (OEA) petição contra o Estado brasileiro, relativa ao caso de violência 
doméstica por ela sofrida (caso Maria da Penha n. ${ }^{\circ}$ 12.051). Penha sofreu uma tentativa de homicídio por parte de seu marido, que atirou em suas costas, deixando-a paraplégica. Desde 1983, época em que a tentativa de homicídio ocorreu, o agressor ficou impune sem nenhuma condenação. Diante disso, os peticionários CEJIL e CLADEM apresentaram o caso à CIDH e denunciaram a tolerância da violência doméstica contra Maria da Penha por parte do Estado brasileiro, pelo fato de não ter adotado, por mais de quinze anos, medidas efetivas necessárias para processar e punir o agressor, apesar das denúncias da vítima (BRASIL, 2010, pág. 427)

Por meio da análise do quinto relatório ao abordar as violações de direitos humanos de alguns grupos minoritários destaca a integridade física, vida e liberdade da mulher, a integridade física e igualdade racial e a integridade e liberdade de orientação sexual. Neste relatório é visível identificar dados que apresentam violações de direitos humanos contra mulheres, negros e LGBTOs. Apesar de existir segundo esses documentos uma dificuldade de se conseguir dados de violações de direitos humanos com esses grupos é possível perceber que a discriminação é um fator de motivação para as violações aos direitos humanos e um obstáculo a ser superado.

A conscientização de mulheres, negros e LGBTOs de que seus direitos são violados levou os relatórios nacionais sobre direitos humanos no Brasil a observarem que as demandas para superar as violações dos grupos minoritários são específicas e que precisam ser contempladas caso as políticas públicas queiram ser efetivas em seu propósito de garantir direitos.

A discriminação que mulheres, negros e LGBTOs sofrem tem por base a distinção que resulta numa desigualdade ou injustiça. Discriminar é excluir, negar cidadania, a democracia e os próprios direitos humanos (MORENO, 2000). No entendimento de Bobbio (2002) a discriminação é uma diferenciação que nega o princípio fundamental de justiça uma vez que devem ser tratados de modo igual aqueles que são iguais.

O quinto relatório apresenta mortes de mulheres ocorridas em diferentes contextos sociais e políticos. Isto posto, entendemos que o feminicídio é apresentado como uma forma de discriminação que tem base o gênero, e se baseia num continuumde terror, uma extensa gama de manifestações de violência e privação a que as mulheres são submetidas ao longo de suas vidas (MORENO, 2000). 
Faz-se necessário ressaltar que a partir da análise dos quatro relatórios é possível constatar uma omissão do Estado, pois segundo Moreno (2000) o Estado não tem uma política seria voltada aos direitos humanos.

O fenômeno da discriminação se repete quando se observa as relações de gênero e raciais no país. Um exemplo dessa situação segundo os quatro relatórios refere-se as relações raciais, ou seja, mesmo o Brasil sendo uma sociedade democrática, existe ainda uma distribuição desigual de direitos não apenas com relação à educação, moradia, alimentação, segurança, mas também o direito à vida (CARVALHO, 2012).

Contribuindo com essa reflexão, Nascimento (1979) nos alerta afirmando que o negro está destinado ao aniquilamento, à exclusão e ao extermínio, no contexto de uma lógica que é colonialista, branca e violenta. Nas palavras do autor:

Ao longo da época da escravidão 1530-1888, o Brasil realizou uma política de liquidação sistemática do Africano. Desde a abolição legal da escravidão em 1888 até o presente, este regime foi continuado por meio de vários mecanismos bem definidos de opressão e de extermínio, deixando a supremacia branca sem ameaças no Brasil (NASCIMENTO, 1979, p.59).

Nesse sentido, a condição da população negra na sociedade brasileira se configura numa situação de exclusão que impede que seus direitos sejam contemplados. Segundo os relatórios nacionais na comparação da população branca com a população negra é possível identificar desigualdades significativas como, por exemplo, o acesso à educação, conforme afirmar os relatórios:

A taxa de analfabetismo entre a população branca de 15 anos ou
mais é de $6,1 \%$, enquanto que para os negros e pardos é de 14,1
$\%$, ou seja, uma diferença de $131,1 \%$. A desproporção entre
analfabetos negros e pardos e brancos se mantém grande entre
todas as regiões e estados do país. A maior diferença entre
analfabetos negros e pardos e brancos está na região sul
$(+115,9 \%)$ e a menor na região nordeste $(+43,1 \%)$ (BRASIL,
2010 p. 22$)$.

Além disso, existem regiões no Brasil onde a violência contra a população negra atinge números maiores se comparadas com outras regiões do país, os relatórios apontam, por exemplo, que as regiões Norte e Centro-Oeste possuem as maiores taxas de mortalidade por homicídio por cor/raça com relação à 
população preta e parda. Os agentes oficiais também são analisados nos relatórios, estes que deveriam proteger a população acabam por constituir um padrão na morte de jovens negros no país. Segundo dados dos relatórios as maiores vítimas de policiais em serviço são os jovens negros. Isso pode caracterizar o que o movimento negro chama de genocídio da juventude negra no Brasil.

Apesar de que o genocídio na compreensão do fenômeno de violência contra negros, não é apenas considero a violência letal, mas as formas violentas não visíveis que impossibilitam as condições de vida da população negra como um todo e contribui para as violações de direitos humanos dessa população.

No caso da violência contra LGBTOs no Brasil existe uma dificuldade significativa no que tange a coleta de dados sobre as violações de direitos humanos desse grupo uma vez que existem poucas pesquisas reconhecidas sobre violência que tem por motivação a orientação sexual. É importante reconhecer a necessidade de mais pesquisas nessa aérea para que possamos pensar de maneira propositiva em políticas públicas voltadas aos direitos humanos.

A discriminação em relação à orientação sexual fora dos ideários heterossexistas são alvo de discussão nos relatórios nacionais sobre direitos humanos. A homofobia é apresentada como um fator que leva a atitudes e manifestações contrárias aos direitos desses grupos.

Segundo Amadi (2012), a homofobia é caracterizada de sentimentos negativos em relação a lésbicas, gays, bissexuais, transgêneros ou pessoas que não se enquadram nos padrões heteronormativos da sociedade.

A discriminação contra gays, bissexuais, lésbicas, transexuais e travestis é reconhecida pelos indivíduos quando questionados sobre seus próprios preconceitos, de acordo com os dados: $29 \%$ dos entrevistados tem preconceitos contra travestis, $28 \%$ contra transexuais, $27 \%$ contra lésbicas e bissexuais e $26 \%$ contra gays As consequências desse fenômeno da discriminação reverberam nas violações de direitos humanos desse grupo (AMADI, p. 21, 2012).

Nesse sentido, as políticas em relação à proteção aos grupos minoritários necessitam de um enfoque mais específico para cada grupo, pois as necessidades são diversas. A percepção presente nos relatórios nacionais sobre direitos humanos é de que o Estado deve provir com políticas públicas que garantam os direitos de grupos que sofrem com as violência e formas de evitar e superar a discriminação. Nos relatórios estão presentes como proposta de 
cumprimento dos direitos humanos a defesa de que esses se transformassem em políticas de estado e não apenas de governo, conforme é possível observar no terceiro relatório:

Para organizações e militantes de Direitos Humanos, fundamental é a reafirmação das políticas de Direitos Humanos como políticas de estado e não de governo, e manutenção e ampliação da autonomia das instituições, organizações e movimentos de proteção e defesa dos Direitos Humanos (BRASIL, 2007, p. 17).

Portanto, vemos que os relatórios caminham nessa direção de contemplar os diferentes grupos sociais e minoritários, principalmente quando estes focam em analisar violações de direitos humanos sofridos pela população negra, mulheres e LGBTOs de modo a proteger grupos minoritários e combater a discriminação de que são alvos.

Nesse sentido, apesar dos grupos minoritários serem contemplados nos relatórios nacionais sobre direitos humanos no Brasil ainda é importante reconhecer que no contexto desses grupos existem formas de discriminação diversas que ainda não foram contempladas nos relatórios.

As violações aos Direitos Humanos no Brasil conforme apontam os relatórios nacionais sobre direitos humanos impede que a proposta de um país verdadeiramente democrático seja efetivada. Além de não existir um interesse dos governantes para a consumação desses direitos, segundo os relatórios, existe a falta de domínio técnico desses mesmos governantes no que tange à criação de políticas para desenvolver os Direitos Humanos no país:

[...] o problema não é apenas a falta de vontade dos governantes, mas falta capacidade política e técnica para desenvolver políticas de Direitos Humanos, que contribui para um déficit de democracia (BRASIL, 2007, p. 17).

Nesse sentido, necessitamos de mais pesquisas na área de direitos humanos, pois a partir dessas poderemos repensar a formação humana no contexto de uma sociedade democrática. 


\section{CONSIDERAÇÕES FINAIS}

A partir dos relatórios nacionais sobre direitos humanos no Brasil é possível concluir que as violações de direitos humanos de mulheres, negros e LGBTOs tem por base a discriminação. No levantamento de dados sobre o machismo, racismo e homofobia a partir dos relatórios nacionais várias fontes teóricas e documentais auxiliam para a reflexão sobre discriminação no país e geram a possibilidade de criação de políticas públicas para esses grupos, possibilitando assim visibilidade no que ao exercício de sua cidadania.

O indicativo presente nos Relatórios Nacionais sobre direitos humanos refere-se à mudança na concepção de universalidade do direito, pois esse pressuposto universalizante de igualdade perante a lei não pode ignorar as injustiças sociais das realidades nas quais o sujeito está inserido.

Além disso, a criação ocidental dos direitos humanos precisa se aplicar em realidades diferentes como é a dos países orientais que tem outros princípios de dignidade da pessoa humana e outros valores que também precisam ser contemplados para que os direitos humanos tenham uma efetividade nesses países levando em conta sempre o pressuposto de que todas as culturas são relativas e a necessidade de diálogos interculturais (SANTOS, 1997).

A discriminação é um obstáculo que precisa ser enfrentado em defesa da dignidade da pessoa humana. A necessidade de mais pesquisas a partir de abordagem teórica sobre a discriminação precisam ser realizadas com o intuito de um entendimento científico mais profundo sobre este fenômeno social tão reincidente no percurso histórico do país.

Apesar de diversos estudos sobre a discriminação racial e de gênero no país ainda existem muitos problemas sociais que precisam ser resolvidos. $\mathrm{E}$ no caso da discriminação que tem por motivação a sexualidade que não se adequa a heteronormatividade existe um desafio ainda maior de fomentação de estudos que abordem o tema. A criminalização da homofobia pelo STF (Supremo Tribunal Federal) foi um passo importante no levantamento de dados, na realização de pesquisas e na proteção de LGBTOs.

$\mathrm{Na}$ análise comparativa dos quatro relatórios nacionais foi possível observar que o recorte que trata de grupos minoritários tem ganhado visibilidade na produção dos textos. Para tanto, a dignidade da pessoa humana precisa ser preservada e defendida, o combate à discriminação, a criação de 
políticas públicas e a educação em direitos humanos são passos importantes para a emancipação de negros, mulheres e LGBTOs.

No entender desses documentos a questão dos direitos humanos pode auxiliar na formação mais humana do sujeito social e este por sua vez poderá perceber a alteridade como algo ético e moral.

\section{REFERÊNCIAS BIBLIOGRÁFICAS}

BARATTO, Marcia. Multiculturalismo e direitos humanos. Conexão Política, Teresina, v. 3, n. 15, p.5-17, jan. 2014.

BRAGATO, Fernanda Frizzo; ADAMATTI, Bianka. Igualdade, não discriminação e direitos humanos. Revista de Informações Legislativas, Rio Grande do Sul, v. 204, n. 51, p.91-108, out. 2014.

. Direitos humanos e diálogos interculturais: Possibilidades e limites.

2009. 167 f. Tese (Mestrado) - Curso de Ciência Política, Universidade Estadual de Campinas, Campinas, 2009.

BRASIL. Comitê Nacional de Educação em Direitos Humanos PlanoNacional e Educação em Direitos Humanos. Brasília: Secretaria Especial dos Direitos Humanos; Ministério da Educação, 2003.

BRASIL. NEV/USP. (Org.). I Relatório nacional sobre Direitos Humanos no Brasil. São Paulo: USP, 2002.

BRASIL. NEV/USP. (Org.). II Relatório nacional sobre Direitos Humanos no Brasil. São Paulo: USP, 2005.

BRASIL. NEV/USP. (Org.). III Relatório nacional sobre Direitos Humanos no Brasil. São Paulo: USP, 2007.

BRASIL. NEV/USP. (Org.). IV Relatório nacional sobre Direitos Humanos no Brasil. São Paulo: USP, 2010.

BRASIL. NEV/USP. (Org.). V Relatório nacional sobre Direitos Humanos no Brasil. São Paulo: USP, 2012. 
GUERREIRO, R. O mundo tribal de Abdias do Nascimento. In:NASCIMENTO, A. Orixás: os deuses vivos da África. Rio de Janeiro: Teatro Experimental do Negro, 1989.

LIMA, Firmino Alves. Contribuições para uma teoria da discriminação nas relações de trabalho. 2010. 389 f. Tese (Doutorado) - Curso de Direito, Universidade de São Paulo, São Paulo, 2010.

MOREIRA, Nathalia Lutterbach Pires. A linha tênue entre os direitos humanos e o multiculturalismo. Revista do Cepej, Salvador, v. 19, n. 1, p.279-304, jan. 2016 .

MORENO, Jamile Coelho. Conceito de minorias e discriminação. USCS, São Paulo, v. 1, n. 17, p.141-156, jun. 2009.

NASCIMENTO, A. do. Quilombo: vida, problemas e aspirações do negro. São Paulo: Edições NO.1, 1948.

NUNES, Maria do Rosário. Caderno de Educação em Direitos Humanos. Brasília: Secretaria de Direitos Humanos da Presidência da República, 2013.

PEREIRA, Cícero; TORRES, Ana Raquel Rosas; ALMEIDA, Saulo Teles. Um Estudo do Preconceito na Perspectiva das Representações Sociais: Análise da Influência de um Discurso Justificador da Discriminação no Preconceito Racial. Psicologia: Reflexão e Crítica, Goiás, v. 16, n. 1, p.95-107, jan. 2003.

PIOVESAN, Flavia. Ações afirmativas da perspectiva dos direitos humanos. Cadernos de Pesquisa, São Paulo, v. 35, n. 124, p.43-55, jan. 2005.

SANTOS, Boaventura de Sousa. Por uma concepção multicultural de direitos humanos. Revista Crítica de Ciências Sociais, Coimbra, v. 48, n. 1, p.11-32, jun. 1997.

2013.

Se Deus fosse um ativista dos direitos humanos. São Paulo: Cortez,

SANTOS, A. C. A lei do dosejo: Direitos Humanos e Minorias Sexuais em Portugal. Porto: Afrontamento, 2005.

TORRES, Marco Antonio. Direitos humanos LGBTQs (Lésbicas, gays, bissexuais, travestis e transexuais) na educação e as lógicas heterossexistas. Diásporas, Diversidades, Deslocamentos, Ouro Preto, p.1-10, ago. 2010. 
WOLLSTONECRAFT, Mary. Reinvindicação dos direitos da mulher. Trad. Ivania Pocinho Motta. São Paulo: Boimtempo, 2016.

Recebido em 24/04/2019 Aprovado em 15/09/2019 